\title{
RESPONSE CURVES IN SELECTION EXPERIMENTS
}

\author{
J. W. JAMES \\ School of Wool Technology, The University of New South Wales, \\ Kensington, Australia
}

Received 21.ix.64

\section{INTRODUCTION}

IN most selection experiments the only curve fitting necessary is the fitting of a straight line to estimate the average rate of response in the first few generations. Occasionally, however, the need to fit other curves does arise. Thus Dempster et al. (1952), Yamada et al. (1958) and Rahnefeld et al. ( 1963 ) all fitted polynomial curves to generation means. The present discussion arose from an attempt to estimate limits to which generation means were tending in lines of Drosophila melanogaster selected for abdominal bristle number by McBride and Robertson ( 1963 ).

Quadratic curves fitted by least squares using orthogonal polynomials reached their maxima a few generations before selection was discontinued, suggesting that response to selection had ceased and a decline had begun. A similar result was obtained by Yamada $e t$ al. (1958). However, the Drosophila data strongly indicated that response had been continuing, and this drew attention to the fact that polynomial curves were not appropriate for the purpose.

Two theories of selection limits for traits controlled by additive genes (Robertson, I96o; James, 1962) have led to selection response curves of the form

$$
y=\alpha+\beta \rho^{x}
$$

where $y$ is the generation mean, $x$ the number of generations of selection, and $\alpha, \beta, \rho$ are parameters of the curve. These parameters have different interpretations in the two theories, but since this exponential regression curve describes a progressive decline in rate of response as a limit is approached, it may be more appropriate than polynomial curves for fitting to selection responses, regardless of the validity of either theory.

It was therefore decided to compare the exponential regression with a parabola (which also has three adjustable parameters) as a description of selection responses in experiments on different organisms. These comparisons are the subject of this paper.

\section{SOURCES OF DATA}

The data for the four comparisons made were obtained from the following sources:

(i) The line of mice selected for large body size by Falconer (1953). The generation means were read from his fig. I, probably with some inaccuracy. Generation I was taken as a base generation 
because of the change in selection procedure which was made at this point.

(ii) The line of hens selected for increased shank length by Lerner and Dempster (195I), the means of successive generations being taken from the table given by Lerner (1954).

(iii) The flock of hens selected for increased egg production by Dempster et al. (1952), for which Tebb (1958) gave a table of annual means. Only data up to 1948 were included because of the very large drop in production which was caused by disease in 1949. In this experiment annual means are not identical with generation means.

(iv) The CA line of Drosophila melanogaster selected for high abdominal bristle number by $\mathrm{McBride}$ and Robertson ( 1963 ). The actual generation means were provided by $\mathrm{Dr} \mathrm{McBride}$.

Table I gives the figures on which the analyses were performed. All means are expressed as deviations for the mean of the base generation, except for the shank length line, where deviations from a control

TABLE I

Coded generation means for four selection experiments

\begin{tabular}{|c|c|c|c|c|}
\hline \multirow{2}{*}{ Generation } & \multicolumn{4}{|c|}{ Experiment } \\
\hline & I & II & III & IV \\
\hline o & o & o & 0 & 0 \\
\hline I & 0.8 & 0.30 & $8 \cdot 0$ & $2 \cdot 74$ \\
\hline 2 & 0.9 & 0.37 & $53 \cdot 9$ & $4 \cdot 36$ \\
\hline 3 & $2 \cdot I$ & 0.83 & 69.5 & 7.02 \\
\hline 4 & $1 \cdot 7$ & 0.83 & $84 \cdot 6$ & $9 \cdot 00$ \\
\hline 5 & $1 \cdot 2$ & $1 \cdot 04$ & $66 \cdot 9$ & $11 \cdot 90$ \\
\hline 6 & $2 \cdot 5$ & $1 \cdot 32$ & $36 \cdot 9$ & $12 \cdot 20$ \\
\hline 7 & $3 \cdot 2$ & $1 \cdot 36$ & $62 \cdot 1$ & I5.54 \\
\hline 8 & $2 \cdot 0$ & $1 \cdot 27$ & $78 \cdot 8$ & I 6.54 \\
\hline 9 & $2 \cdot 7$ & 0.96 & $96 \cdot 4$ & $17 \cdot 18$ \\
\hline 10 & $3 \cdot 1$ & $1 \cdot 07$ & $9^{1} \cdot 6$ & $17 \cdot 85$ \\
\hline I I & $\ldots$ & $I \cdot 25$ & $73 \cdot 8$ & 18.04 \\
\hline 12 & $\ldots$ & $1 \cdot 52$ & 101 6 & 18.62 \\
\hline 13 & $\ldots$ & I. 49 & $97 \cdot 7$ & $19 \cdot 16$ \\
\hline 14 & $\ldots$ & I.33 & $86 \cdot 6$ & $20 \cdot 4^{2}$ \\
\hline 15 & $\ldots$ & $\ldots$ & $90 \cdot 2$ & $21 \cdot 70$ \\
\hline 10 & ... & $\ldots$ & 107.6 & $2 I \cdot 3 I$ \\
\hline I 7 & $\cdots$ & ... & ... & $22 \cdot 26$ \\
\hline 18 & $\cdots$ & $\ldots$ & $\ldots$ & $21 \cdot 88$ \\
\hline 19 & $\ldots$ & $\ldots$ & $\ldots$ & $22 \cdot 84$ \\
\hline
\end{tabular}

line have been used, as by Lerner and Dempster (195I). In each case the first observation is taken to be at generation zero, where the population mean is zero.

\section{CURVE FITTING}

Some properties of the exponential curve (I) are worth noting. $\alpha$ is the limit to which $y$ tends as $x$ increases, while $\alpha+\beta$ is the value of 
$y$ at $x=0,-\beta$ being thus the total advance. The estimates of $\alpha$ and $\beta$ should be of opposite sign but roughly equal in magnitude since $y$ was set at zero for $x=0$. $\rho$ measures the rate of decay of response, since the gain in generation $x+1$ is a fraction $\rho$ of that in generation $x$. If the equation is written

$$
y=\alpha+\beta\left(\frac{1}{2}\right)^{x / y}
$$

then $\gamma$, which equals $-\frac{\log 2}{\log \rho}$, is a time-scale factor, measuring the half-life of the selection process.

The parabolas were fitted by least squares using the tables of orthogonal polynomials given by Fisher and Yates (1957). The exponential regression was fitted by the least squares method of Stevens (195I). This is an iterative method, requiring a starting value of $r$ (estimate of $\rho$ ) which was obtained by autoregression (Finney, I958). Such estimates are biased (Patterson, 1958) but this was not of much consequence in these instances. Iteration was discontinued when the adjustment to $r$ was less than o.0oI in absolute value. Approximate standard errors for $a, b, r$ (estimates of $\alpha, \beta, \rho$ ) were computed from formulæ given by Stevens (I95I). It was not considered worthwhile to set confidence limits on $\rho$ by the method of Williams (1962).

Estimates of half-lives were obtained as

$$
c=-\frac{\log 2}{\log r}
$$

and approximate standard errors for $c$ calculated by multiplying those

for $r$ by $\frac{d c}{d r}=\frac{\log 2}{r(\log r)^{2}}$.

The comparison in any case was adjudged to favour the curve for which the sum of squares of the deviations of the observed values from the regression was the smaller.

\section{RESULTS}

In all four cases the exponential regression gave a closer fit to the observations than did the parabola. The efficiency of the parabola relative to the exponential curve, measured as a ratio of sums of squares of deviations, was in each case

$$
\begin{array}{llll}
\text { (I) } 0.985 & \text { (II) } 0.819 & \text { (III) } 0.886 & \text { (IV) } 0.662 .
\end{array}
$$

Table 2 gives the parameter estimates for both curves and the residual sums of squares for the four experiments. Clearly the exponential curve may be substantially better than the parabola as a description of the data, the improvement being most impressive in the Drosophila data and least impressive in that of the mice. 
In two experiments (shanks and bristles) the parabola gave a significantly better fit than a straight line, indicating non-linearity of response. These were also the experiments in which the exponential regression gave most improvement over the parabola. In Falconer's mouse selection there was no evidence of non-linearity. However, in the line selected for egg production, the parabola bordered on being significantly better than a straight line $(0 . \mathrm{I}>\mathrm{P}>0.05)$. Unfortunately no exact test is known for comparing an exponential regression with a

TABLE 2

$$
\begin{aligned}
& \text { Estimates of parameters and standard errors of the fitted curves } \\
& \qquad \begin{array}{l}
\mathrm{y}=A+B \mathrm{x}+C \mathrm{x}^{2} \\
\mathrm{y}=\mathrm{a}+\mathrm{br}
\end{array} \\
& \text { with residual sums of squares }
\end{aligned}
$$

\begin{tabular}{|c|c|c|c|c|}
\hline \multirow{2}{*}{ Parameters } & \multicolumn{4}{|c|}{ Experiment } \\
\hline & I & II & III & IV \\
\hline $\begin{array}{l}\mathbf{A} \\
\mathbf{B} \\
\mathbf{C}\end{array}$ & $\begin{array}{r}0.20 \pm 0.42 \\
0.47 \pm 0.19 \\
-0.02 \pm 0.02\end{array}$ & $\begin{array}{c}0.09 \pm 0.12 \\
0.23 \pm 0.04 \\
-0.01 \pm 0.003\end{array}$ & $\begin{array}{r}15 \cdot 7 \pm 11 \cdot 5 \\
11 \cdot 30 \pm 3 \cdot 34 \\
-0.40 \pm 0.20\end{array}$ & $\begin{array}{c}0.45 \pm 0.48 \\
2.42 \pm 0.12 \\
-0.068 \pm 0.006\end{array}$ \\
\hline Sum of squares & $2 \cdot 30$ & 0.41 & $439 \mathrm{I}$ & เo.49 \\
\hline $\begin{array}{l}a \\
b \\
r\end{array}$ & $\begin{array}{r}3 \cdot 4^{8} \pm I \cdot 33 \\
-3 \cdot 36 \pm I \cdot 19 \\
0.84 \pm 0 \cdot 12\end{array}$ & $\begin{array}{r}1 \cdot 39 \pm 0.11 \\
-1.44 \pm 0.15 \\
0.76 \pm 0.057\end{array}$ & $\begin{array}{r}94.6 \pm 9.11 \\
-92.2 \pm 14.02 \\
0.77 \pm 0.078\end{array}$ & $\begin{aligned} & 24.9 \pm 0.72 \\
&-25.4 \pm 0.65 \\
& 0.88 \pm 0.008\end{aligned}$ \\
\hline Sum of squares & $2 \cdot 24$ & 0.34 & 3829 & $6 \cdot 9 \mathrm{I}$ \\
\hline
\end{tabular}

straight line. But if the improvement in fit of the exponential curve over a straight line fit is compared with the mean square for deviations from the exponential curve, $\mathrm{F}$ is found to be 6.2 while the 0.05 point of $\mathrm{F}$ is $4 \cdot 6$. Though the test is not strictly valid, it does compare the three parameters of the exponential curve with the two of the straight line, and seems indicative of genuine non-linearity. It is noteworthy that in these four experiments, the better the fit of a parabola as compared to a straight line, the better is the fit of the exponential curve as compared with the parabola.

One of the most interesting points is the rate at which selection response declines. This is perhaps most easily appreciated from the half-life, the time taken to achieve half the ultimate gain. The

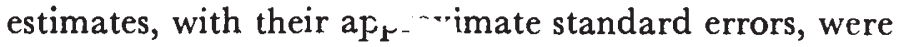

$$
\begin{array}{llll}
\text { (I) } 4.04 \pm 3.37 & \text { (II) } 2 \cdot 57 \pm 0.7 \mathrm{I} & \text { (III) } 2 \cdot 70 \pm \mathrm{I} \cdot 06 & \text { (IV) } 5 \cdot 52 \pm 0.4 \mathrm{I}
\end{array}
$$

The most striking point about these estimates is their smallness. For instance it would seem that the total advance is not likely to exceed twice the gain achieved in the first four or five generations. The 
estimates are clearly too small to be compatible with predictions from the theories of Robertson (1960) and James (1962). Robertson's theory gives the half-life as $\mathrm{I} \cdot 4 \mathrm{~N}$ where $\mathrm{N}$ is the effective population size, while James's theory gives it as $0.35 / \mathrm{I}_{0} h^{2}$, where $h^{2}$ is the heritability of the character selected, and $\mathrm{I}_{0}$ is the intensity of natural selection for the character in the base population, measured by the criterion of Haldane (1954). Approximate values of $N$ are available for these experiments and lead to half-life estimates from Robertson's theory of
(I) $33 \cdot 6$
(II) $16 \cdot 8$
(III) 98
(IV) $2 \mathrm{r} \cdot 8$.

While heritabilities are available, there are no direct estimates of $I_{0}$ to calculate half-lives according to James's theory. However, the values of $I_{0}$ corresponding to the estimated half-lives are
(I) 0.22
(II) 0.34
(III) $0 \cdot 43$
(IV) $0 \cdot 13$.

These values are obviously too large. By considering changes in fitness as selection proceeded, Latter and Robertson (1962) estimated

TABLE 3

Estimates and standard errors of parameters of the curve $\mathrm{y}=\mathrm{a}+\mathrm{br}^{\mathrm{x}}$ fitted to early generations

\begin{tabular}{|c|c|c|c|c|}
\hline \multirow{2}{*}{ Parameters } & \multicolumn{4}{|c|}{ Experiments } \\
\hline & I & II & III & IV \\
\hline $\begin{array}{l}a \\
b \\
r\end{array}$ & $\begin{array}{r}2 \cdot 28 \pm \mathrm{I} \cdot 01 \\
-2 \cdot 26 \pm 0.97 \\
0.69 \pm 0.28\end{array}$ & $\begin{array}{r}3 \cdot 18 \pm 2 \cdot 36 \\
-3 \cdot 18 \pm 2 \cdot 31 \\
0 \cdot 92 \pm 0 \cdot 07\end{array}$ & $\begin{array}{r}75.9 \pm 12.3 \\
-81.8 \pm 20.6 \\
0.60 \pm 0.19\end{array}$ & $\begin{array}{r}30.68 \pm 5.14 \\
-30.94 \pm 4.86 \\
0.91 \pm 0.022\end{array}$ \\
\hline
\end{tabular}

$I_{0}$ for bristle number as 0.04 , while James (1962) similarly estimated $I_{0}$ for shank length as $0 \cdot 12$. Neither theory gives predictions which agree very well with the results, though this is not surprising, since both authors point out that the predictions from their theories are of the nature of upper limits.

However, although neither of the theories which led to the use of the exponential curve predicts the parameters very well, the exponential curve itself may still provide a good description of selection progress.

From the practical standpoint of animal breeding one interesting possibility is that of predicting the ultimate limit of selective advance from the responses observed during the early generations. With this in mind, the exponential regression was fitted to the data for the first part of each experiment, the generations used being
(I) $0-6$
(II) 0 -7
(III) $0-9$
(IV) o-Io.

The estimates of $a, b, r$ from these early generations are given in table 3. It will be noted that, as judged by standard errors, the two 
estimates are compatible in all cases (they are not independent), but may be quite different. Thus the ratios of part- to full-period estimates are for the limits

$$
\begin{array}{llll}
\text { (I) } 0.67 & \text { (II) } 2.2 \text { I } & \text { (III) } 0.89 & \text { (IV) I } 22 .
\end{array}
$$

An early estimate in the shank length experiment would have been disastrously optimistic, predicting a total gain of more than twice that ultimately achieved. It would seem that little of value is gained by attempts at early prediction of the total advance.

\section{DISCUSSION}

This study resulted from an attempt to estimate the limits to gain from selection in a particular case, in which selection had to be discontinued before these limits were reached. Such a problem is unlikely to be of much importance in laboratory experiments. However, in selection for economic characters in domestic animals it may well be important at some time to estimate how much further progress may be expected to follow from the continuation of methods currently in use. Early prediction of such limits would seem to be unreliable, as judged from the present results, but the situation may not be so bad at the stage when rate of response has declined sufficiently to make a change in breeding methods desirable in the near future.

It seems that the exponential curve gives a better description of responses than does the parabola, especially when response is appreciably non-linear. Though this is of dubious theoretical significance, it may be of some practical interest. Thus, since the parabola fitted by Dempster et al. (1952) was not significantly better than a straight line, Lerner (1958) wrote " as a matter of fact, it is impossible to determine for the full annual record whether or not gains have been produced at a constant rate or whether they are still being obtained at all". From the comparison of the exponential regression with a straight line for the data of this experiment (III) there seems no doubt that responses to selection may safely be said to have decreased. Lerner's dilemma appears to have arisen from the use of an inappropriate alternative to the straight line. The use of polynomial regressions to test non-linearity of response is of doubtful value except in clear-cut cases. Negative results of such tests must be interpreted very cautiously.

Though neither Robertson (1960) nor James (1962) would have expected his theory to do more than provide upper limits to total selective gains in such experiments as analysed here, it is still worth making the point that the agreement of these theories with observation is very poor. It is clear that there is still no theoretical basis for making accurate predictions of how much response may reasonably be expected to follow continued selection. 


\section{SUMMARY}

Exponential and parabolic regressions were compared as descriptions of the progress of selection in four experiments. The exponential regression was consistently superior. Early prediction of selection limits was shown to be unreliable. Two theoretical models were found to give poor predictions of the progress under selection.

\section{REFERENCES}

DEMPSTER, E. R., LERNER, I. M., AND LOWRY, DOROTHY C. 1952. Continuous selection for egg production in poultry. Genetics, 37, 693-708.

FALCONER, D. S. I953. Selection for large and small size in mice. 7. Genetics, 51 , 470-50I.

FINNEY, D. J. 1958. The efficiencies of alternative estimators for an asymptotic regression equation. Biometrika, 45, 370-388.

Fisher, R. A., AND yates, F. 1957. Statistical Tables. 5th Ed. Oliver and Boyd, Edinburgh.

IIALdANE, J. B. S. 1954. The measurement of natural selection. Proc. 9th Int. Congr. Genet., Part 1, 470-487.

JAMEs, J. w. 1962. Conflict between directional and centripetal selection. Heredity, $17,487-499$.

LATTER, B. D. H., AND ROBERTSON, A. I962. The effects of inbreeding and artificial selection on reproductive fitness. Genet. Res., 3, 1 10-138.

LERner, I. M. 1954. Genetic Homeostasis. Oliver and Boyd, Edinburgh.

LERnER, I. M. 1958. The Genetic Basis of Selection. John Wiley and Sons, New York.

LERNER, I. M., AND DEMPSTER, E. R. I95I. Attenuation of genetic progress under continued selection in poultry. Heredity, 5, 75-94.

MCBRIDE, G., AND ROBERTSON, A. 1963. Selection using assortative mating in Drosophila melanogaster. Genet. Res., 4, 356-369.

PATTERSON, H. D. I958. The use of autoregression in fitting an exponential curve. Biometrika, 45, 389-400.

RAHNEFELD, G. W., BOYLAN, W. J., COMSTOCK, R. E., AND MADHo, SINGH. 1963. Mass selection for post weaning growth in mice. Genetics, $48,1567-1583$.

robertson, A. Ig6o. A theory of limits in artificial selection. Proc. Roy. Soc. B., I53, 234-249.

stevens, w. L. 1951. Asymptotic regression. Biometrics, 7, 247-267.

TEBB, G. 1958. Intra-generation inbreeding effects in a poultry flock selected for egg production. Heredity, 12, 285-299.

williams, E. J. I962. Exact fiducial limits in non-linear estimation. $\mathcal{F}$. Roy. Statist. Soc. B., 24, 1 25-139.

YAMADA, Y., BOHREN, B. B., AND CRITTENDEN, L. B. 1958. Genetic analysis of a White Leghorn flock apparently plateaued for egg production. Poult. Sci., 37, $565-580$. 